\title{
ISOLASI DAN IDENTIFIKASI BEBERAPA KOMPONEN KIMIA EKSTRAK DIETIL ETER STANDAR HERBA Oxalis corniculata L.
}

\author{
Herwin, Rachmat Kosman, Muzakkir Baits \\ Fakultas Farmasi Universitas Muslim Indonesia Makassar \\ Email : herwinfarmasi@gmail.com.
}

\begin{abstract}
A research have been conducted about isolation and identification some chemicals components in diethyl ether standard ekstract of Oxalis corniculata L. herb from Mamuju of West Sulawesi with purpose isolation and identification some chemicals components standard ekstract diethyl ether Oxalis corniculata L. herb based on fitochemistri parameters on the way kualitatife dan kuantitatife. Based on isolation with fitochemistri parameters of kuantitatife that standard diethyl ether ekstract $38 \mathrm{gram}$. Based on isolation and identification some chemical components obtained that dietyl ether ekstract of thin layer cromatography obtained chemicals components flavanoid at Rf 0.47 value with reagent Antimo (III) cloride, components alcaloids at $\mathrm{Rf} 0.86$ value with reagents chemicals dragendorf, components chemicals steroids at Rf 0.90 with reagents chemicals Liebermann-Bouchard and kualitatife analisis at specific parameter in organoleptic that colour ekstract green, aromatis, smell, a tick form idication obtained alcaloids, steroids and flavanoids.
\end{abstract}

Key Word : Diethyl Ether Oxalis corniculata L. Ekstract, Isolation And Identification, Kualitatife and Kuantitatife.

\section{PENDAHULUAN}

Peningkatan kebutuhan obat tradisional merupakan peluang besar untuk pengembangan budidaya dan agrobisnis tumbuhan obat dan industri pengolahannya. Dimana dari segi efek samping diakui bahwa obat tradisional memiliki efek samping yang relatif kecil dibandingkan dengan obat modern. Maka dari itu sediaan obat tradisional dalam pemanfaatannya sangat diperlukan pengujian aktivitas dan pengujian pra-klinis untuk mengetahui khasiat, dosis dan keamanan obat tradisional tersebut. Salah satu tanaman yang sering digunakan oleh masyarakat dalam pengobatan tradisional khususnya masyarakat mamuju adalah belimbing tanah yang digunakan sebagai obat batuk dan penurun panas bagi anak-anak. Dimana bagian yang dapat digunakan sebagai bahan obat adalah dalam bentuk herbanya. Namun secara ilmiah pemanfaatan dan kandungan kimia yang terdapat dalam herba belimbing tanah sebagai obat tradisional belum terealisasikan. Untuk 
Isolasi dan identifikasi beberapa komponen kimia ekstrak dietil eter standar herba Oxalis corniculata $L$.

mengetahui adanya khasiat obat tradisional dalam suatu tanaman atau tumbuhan maka perlu adanya mengetahui beberapa golongan komponen kimia yang terkandung dalam tumbuhan atau tanaman tersebut, sehingga diperlukan adanya isolasi dan identifikasi golongan beberapa komponen kimia terutama dalam ekatrak herba belimbing tanah yang berpotensial sebagai obat tradisional terutama sebagai antimikroba.

Berdasarkan hal tersebut maka perlu dilakukan isolasi dan identifikasi golongan komoponen kimia ekstrak dietil eter herba belimbing tanah yang terstandarisasi sehingga penggunaannya dalam masyarakat lebih dapat dipertanggungjawabkan.

\section{METODE PENELITIAN}

\section{Tempat dan Waktu Penelitian}

Penelitian dilaksanakan di Laboratorium Fitokimia Fakultas Farmasi Universitas Muslim Indonesia Makassar dengan pengujian isolasi dan identifikasi golongan komponen kimia ekstrak dietil eter standard dan waktu penelitian dimulai pada bulan Juli - Agustus 2013.

\section{Bahan dan Alat Penelitian}

Bahan dalam penelitian ini adalah belimbing tanah (Oxalis corniculata L.) dari Mamuju Sulawesi Barat, air suling, (E.Merck), n-heksan p.a (E.Merk), dietil eter p.a (E.Merk), larutan $\mathrm{NaCl}$ fisiologis $0,9 \%$, metanol p.a, reagen semprot (aluminium klorida, antimo (III) klorida, $\mathrm{FeCl}_{3}$, Dragendorff, Liebermann-Buchard, asam sulfat $10 \%$, uap amonia), $\mathrm{H}_{2} \mathrm{SO}_{4}$ p.a.

Alat yang digunakan dalam penelitian ini adalah timbangan analitik, rotavapor, sentrifuge, oven, bejana maserasi, chamber, corong, corong pisah $500 \mathrm{ml}$, labu ukur $50 \mathrm{ml}$, lempeng kromatografi lapis tipis, penangas air, timbangan kasar, cawan porselen.

\section{Presedur Penelitian}

Belimbing tanah (Oxalis corniculata L.) yang diperoleh dari Mamuju Sulawesi Barat terlebih dahulu disortasi dengan tujuan untuk memisahkan kotoran-kotoran yang melekat pada sampel sehingga sampel yang dibutuhkan sesuai dengan yang diperlukan. Proses pemisahan kotoran dilakukan dengan air mengalir hingga bersih dan diangin-anginkan diudara bebas dan tidak terkena matahari secara langsung.

Isolasi Dan Identifikasi Komponen Kimia Berdasarkan Parameter Fitokimia 
Isolasi dan identifikasi beberapa komponen kimia ekstrak dietil eter standar herba Oxalis corniculata $L$.

\section{Ekstraksi sampel}

Tumbuhan belimbing tanah (Oxalis corniculata L.) ditimbang sebanyak 700 gram kemudian dimasukkan ke dalam wadah maserasi, lalu ditambahkan etanol 96\% (hingga simplisia tersebut terendam) dan dibiarkan selama 5 hari dengan pengadukan sesering mungkin dalam bejana tertutup dan terlindung dari cahaya. Setelah itu disaring dan ampasnya direndam lagi dengan cairan penyari yang baru. Hal ini dilakukan hingga proses ekstraksi sempurna. Hasil penyarian yang didapat kemudian diuapkan dengan menggunakan rotavapor hingga diperoleh ekstrak etanol kental. Ekstrak kental yang diperoleh dihitung kadar ekstrak dan dilakukan standarisasi berdasarkan parameter spesifik dan nOn-spesifik sehingga diperoleh ekstrak terstandar.

Pemisahan secara Kromatografi Lapis Tipis (KLT)

Lempeng KLT diaktifkan dengan pemanasan dalam oven pada suhu $100^{\circ} \mathrm{C}$ selama 30 menit sebelum digunakan. Ekstrak dietil eter herba belimbing tanah ditotolkan pada lempeng KLT ukuran $7 \times 1 \mathrm{~cm}$ dengan menggunakan pipa kapiler. Lalu dielusi dengan menggunakan eluen $\mathrm{n}$-heksan : etil asetat $(2: 1)$ di dalam chamber.
Lempeng dikeluarkan dari chamber diangin-anginkan hingga cairan pengelusinya menguap. Kemudian kromatogram yang dihasilkan diamati nodanya di bawah sinar UV pada panjang gelombang $254 \mathrm{~nm}$ dan 366 nm, serta penampakan noda penyemprotan $\mathrm{H}_{2} \mathrm{SO}_{4} \quad 10 \%$ dan dihitung nilai Rf-nya.

\section{Penentuan parameter fitokimia :}

a. Parameter spesifik dilakukan berdasarkan Penetapan organoleptis ekstrak, meliputi bentuk, bau dan rasa (Depkes RI, 1980).

b. Identifikasi golongan komponen kimia yang aktif antimikroba meliputi pereaksi penampak bercak saponin, flavonoid, dan tanin (Sustrisno, 1993). Untuk penampak bercak beberapa golongan senyawa tertentu yaitu kromatogram disemprot dengan menggunakan pereaksi semprot sebagai berikut :

1. Pereaksi Benedict : pereaksi ini mengurangi atau meniadakan pendaran dari senyawa dengan gugus O-hidroksi; bila flavonoid tidak mempunyai gugus tersebut, maka pendaran tidak berubah atau menjadi lebih intensif.

2. Aluminuim klorida : dipanaskan 
Isolasi dan identifikasi beberapa komponen kimia ekstrak dietil eter standar herba Oxalis corniculata $L$.

kromatogram suhu $110^{\circ} \mathrm{C}$ selama 10 menit dan diamati noda yang berflourosensi pada lampu UV, noda yang berflourosensi kuning adalah senyawa golongan flavanoid.

3. Komarowsky II : dipanaskan kromatogram suhu $110^{\circ} \mathrm{C}$ selama 5-10 menit. Diamati dalam sinar biasa maka yang tampak adalah saponin.

4. Asam oluensulfona : dipanaskan kromatogram suhu $100^{\circ} \mathrm{C}$ sampai $10-20$ menit, kemudian diamati noda pada lempeng maka yang akan tampak bercak berpendar pada sinar UV $366 \mathrm{~nm}$ adalah tanin.

5. Dragendorf- $\mathrm{HCl}:$ Lempeng disemprot sampai penampakan bercak orange adalah alkaloid

6. Yodium-KI Lempeng disemprot dengan pereaksi sampai tampak tembus cahaya dengan warna noda orange kecoklatan adalah alkaloid

7. Liberman-Bauchardat: Setelah lempeng disemprot kemudian dikeringkan di udara tampak bercak berwarna coklat adalah steroid.

\section{HASIL PENELITIAN}

Tabel 1. Hasil Sortasi Herba Belimbing Tanah (Oxalis corniculata L.) Asal Mamuju Sulawesi Barat

\begin{tabular}{c|c|c|c|c}
\hline No. & $\begin{array}{c}\text { Berat Tumbuhan } \\
\text { (gram) }\end{array}$ & $\begin{array}{c}\text { Berat Basah } \\
\text { (gram) }\end{array}$ & $\begin{array}{c}\text { Berat Kering } \\
(\mathbf{g r a m})\end{array}$ & $\begin{array}{c}\text { Kadar Air } \\
(\%)\end{array}$ \\
\hline 1. & 765 & 750 & 700 & 6.66 \\
\hline
\end{tabular}

Tabel 2. Hasil Determinasi Herba Belimbing Tanah (Oxalis corniculata L.) Asal Mamuju Sulawesi Barat

\begin{tabular}{c|c|c|c}
\hline No. & $\begin{array}{c}\text { Nama Tumbuhan } \\
\text { Indonesia }\end{array}$ & $\begin{array}{c}\text { Nama Tumbuhan } \\
\text { Mamuju }\end{array}$ & Nama Species \\
\hline 1. & Calincing & Belimbing Tanah & Oxalis corniculata L. \\
\hline
\end{tabular}

Tabel 3. Hasil Isolasi Simplisia Herba Belimbing Tanah (Oxalis corniculata L.) Asal Mamuju Sulawesi Barat

\begin{tabular}{c|c|c|c|c}
\hline $\begin{array}{c}\text { Berat Simplisia } \\
\text { (gram) }\end{array}$ & $\begin{array}{c}\text { Ekstrak Etanol } \\
\text { (gram) }\end{array}$ & $\begin{array}{c}\text { Ekstrak Etanol } \\
\text { Yang Dipartisi } \\
\text { (gram) }\end{array}$ & $\begin{array}{c}\text { Ekstrak } \\
\text { Dietil Eter } \\
\text { (gram) }\end{array}$ & $\begin{array}{c}\text { Residu } \\
\text { (gram) }\end{array}$ \\
\hline 700 & 75 & 50 & 38 & 8 \\
\hline
\end{tabular}


Isolasi dan identifikasi beberapa komponen kimia ekstrak dietil eter standar herba Oxalis corniculata $L$.

Tabel 4. Hasil identifikasi kandungan kimia ekstrak dietil eter herba belimbing tanah (Oxalis corniculata L.) Asal Mamuju Sulawesi Barat secara kualitatif.

\begin{tabular}{c|l|l|c|c}
\hline No. & Golongan Kimia & \multicolumn{1}{c|}{ Pereaksi } & Warna & Ket \\
\hline 1. & Alkaloid & Dragendorff & Coklat & + \\
\hline 2. & Flavanoid & Antimon (III) Klorida & kuning & + \\
\hline 3. & Terpenoid & $\begin{array}{l}\text { Asam Asetat Anhidrat }+ \\
\text { Asam Sulfat Pekat }\end{array}$ & Orange merah / kuning & - \\
\hline 4. & Steroid & Liebermann-Bouchard $_{3}$ & Coklat & + \\
\hline 5. & Fenolik & $\mathrm{FeCl}_{3}$ & $\begin{array}{l}\text { Biru, biru-violet, merah/ } \\
\text { kuning sampai coklat }\end{array}$ & - \\
\hline 6. & Saponin & Vanilin-Asam Sulfat & \multicolumn{2}{|c}{ - } \\
\hline \multicolumn{2}{l|}{ Keterangan :+ mengandung golongan kom,ponen kimia dan - = tidak mengandung golongan komponen } \\
\hline
\end{tabular}

Tabel 5. Hasil uji organoleptik ekstrak dietil eter herba belimbing tanah (Oxalis corniculata L.) Asal Mamuju Sulawesi Barat berdasarkan parameter spesifik

\section{Parameter Spesifik}

\section{Uji Organoleptik}

\begin{tabular}{c|c|c|c}
\hline Konsistensi & Warna & Bau & Rasa \\
\hline Kental & Hijau & Khas & Sepat \\
\hline
\end{tabular}

Tabel 6. Hasil identifikasi kandungan kimia ekstrak secara kromatografi lapis tipis ekstrak dietil eter herba belimbing tanah (Oxalis corniculata L.) asal Mamuju Sulawesi Barat berdasarkan parameter non-spesifik.

\begin{tabular}{c|l|c}
\hline No. & \multicolumn{1}{|c}{ Parameter Non-Spesifik } & \multicolumn{1}{|c}{ Hasil } \\
\hline & Kandungan kimia ekstrak secara kromatografi lapis tipis & \\
1. & - Flavanoid & $(+)$ pada Rf 0.47 \\
& - Alkaloid & $(+)$ pada Rf 0.86 \\
& - Steroid & $(+)$ pada Rf 0.90 \\
\hline
\end{tabular}

\section{PEMBAHASAN}

Berdasarkan hasil penelitian yang dilakukan diperoleh bahwa herba belimbing tanah (oxalis corniculata L.) hasil identifikasi tumbuhan belimbing tanah (Oxalis corniculata L.) diperoleh bahwa belimbing tanah merupakan tumbuhan asli Indonesia yang bernama Calincing (Oxalis corniculata L.). Dari berbagai macam daerah di
Indonesia tumbuhan ini diberi nama : daun asam kecil / semanggi (Sumatera), calincing / semanggen / semanggi gunung (Jawa), mala-mala (Maluku), (Dalimartha, 2009). Dan berdasarkan hasil survei di daerah Mamuju Sulawesi Barat, tumbuhan ini di beri nama belimbing tanah yang digunakan sebagai obat flu dan batuk untuk anak-anak. Sortasi herba 
Isolasi dan identifikasi beberapa komponen kimia ekstrak dietil eter standar herba Oxalis corniculata $L$.

belimbing tanah (Oxalis corniculata L.) dimaksudkan untuk memperoleh simplisia dengan kadar air dibawah $10 \%$ agar tidak terkontaminasi oleh adanya mikroba patogen. Hasil sortasi 780 gram tumbuhan diperoleh 750 gram berat basah dengan berat kering sebanyak 500 gram dan Determinasi sampel dimaksudkan untuk mengetahui species tanaman atau tumbuhan yang digunakan, hasil determinasi tumbuhan belimbing tanah (Oxalis corniculata L.) dari laboratorium Farmakognoni-Fitokimia Fakultas Farmasi Universitas Muslim Indonesia bahwa sampel penelitian bernama Oxalis corniculata L.

Simplisia kering sebanyak 700 gram diekstraksi dengan metode maserasi menggunakan etanol $96 \%$ diperoleh 75 gram ekstrak etanol kering. Dengan 50 gram ekstrak etanol kering dipartisi dengan metode padat cair diperoleh 38 gram ekstrak dietil eter dan 8 gram residu. Identifikasi kandungan kimia pada ekstrak dietil eter berdasarkan penapisan golongan kimia alkaloid, flavanoid, terpenoid, steroid, fenolik dan saponin diperoleh bahwa ekstrak dietil eter herba belimbing tanah secara kuantitatif mengandung flavanoid menggunakan pereaksi kimia antimo (III) klorida secara kromatografi lapis tipis diproleh nilai $\operatorname{Rf} 0.47$, mengandung alkaloid pada Rf 0.86 menggunakan pereaksi kimia Dragendorff, steroid pada Rf 0.90 menggunakan pereaksi kimia Liebermann-Bouchard dan analisis secara kualitatif pada parameter spesifik terhadap penetapan organoleptik ekstrak berwarna hijau kecoklatan, berbau khas, rasa sepat, konsistensinya kental mengandung alkaloid menggunakan pereaksi kimia Dragendorff, flavanoid menggunakan pereaksi kimia Antimo (III) Klorida dan steroid menggunakan pereaksi kimia Liebermann-Bouchard.

\section{KESIMPULAN}

1. Hasil isolasi ekstrak dietil eter herba belimbing tanah (Oxalis corniculata L.) berdasarkan parameter fitokimia secara kuantitatif bahwa ekstrak dietil eter diperoleh ekstrak standar sebanyak 38 gram dan hasil identifikasi golongan komponen kimia ekstrak dietil eter secara kromatografi lapis tipis mengandung golongan komponen kimia flavanoid pada $\mathrm{Rf} \quad 0.47$ menggunakan pereaksi kimia antimo (III) klorida, mengandung alkaloid pada $\mathrm{Rf} 0.86$ menggunakan pereaksi kimia Dragendorff, dan steroid pada $\mathrm{Rf}$ 0.90 menggunakan pereaksi kimia Liebermann-Bouchard 
Isolasi dan identifikasi beberapa komponen kimia ekstrak dietil eter standar herba Oxalis corniculata $L$.

2. Berdasarkan hasil standarisasi ekstrak secara organoleptik ekstrak berkonsistensi kental, berwana hijau kecoklatan, bau khas, rasa sepat dan secara kualitatif mengandung golongan kompoonen kimia alkaloid, steroid dan flavanoid..

\section{DAFTAR PUSTAKA}

Kathiriya A.K.,, Kuntal D., Joshipura M., and Mandal N., 2010. "Oxalis corniculata Linn. The Plant of Indian subtropics", Herbal Tech Industri, India

Departemen Kesehatan RI, 1980. "Materia Medika Indonesia", Jilid IV, Jakarta

Departemen Kesehatan RI, 1995. "Farmakope Indonesia", Edisi IV, Jakarta

Departemen Kesehatan RI, 2000. "Parameter Standar Umum Ekstrak Tumbuhan Obat",
Edisi I, Dirjen POM Direktorat

Pengawasan Obat

Tradisional, Jakarta

Harborne, J.B., 1987. "Metode Fitokimia Penuntun Cara Modern Menganalisa Tumbuhan", Cetakan II, Diterjemahkan oleh Padinawinata K., dan Soediro I., Penerbit IPB Bandung.

Steenis, Van.C.G.G.J. dkk. 2008. Flora. PT. Pradnya Paramita : Jakarta

Soetarno S., dan Soediro I.S., 1997. "Standarisasi Mutu Simplisia dan Ekstrak Bahan Obat Tradisional", Presidium Temu Ilmiah Nasional Bidang Farmasi

Voight R., 1994. "Buku Belajar Teknologi Farmasi", Diterjemahkan oleh Noerono S., UGM Press, Yoryakarta 